VALVE DISEASE

\section{Prosthetic valve endocarditis}

C Piper, R Körfer`, D Horstkotte

Department of Cardiology, ${ }^{\star}$ Department of Thoracic and

Cardiovascular Surgery, Heart Center North Rhine-Westphalia, Ruhr

University, Bad Oeynhausen, Germany

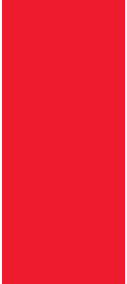

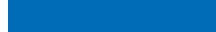

\begin{abstract}
fter 40 years of continuous improvements in the design and materials used for prosthetic heart valves, valve replacement surgery is now performed with low morbidity and mortality. These advantages have been hampered by a few but severe adverse effects; in particular, infections of the prosthetic material continue to be an extremely serious complication occurring with a relatively low but increasing frequency ranging from $0.1-2.3 \%$ per patient year..$^{1-3}$ The prosthesis obviously predisposes to device related infections, especially those caused by novobiocin susceptible, coagulase negative staphylococci, which are able to adhere to a variety of surfaces $^{4}$ and produce an antibiotic resistant biofilm. ${ }^{56}$
\end{abstract}

\section{Definition and frequency}

Prosthetic valve endocarditis (PVE) is an endovascular, microbial infection occurring on parts of a valve prosthesis or on reconstructed native heart valves. ${ }^{7}$ It is recommended to determine whether (a) a mechanical prosthesis, (b) a bioprosthetic xenograft, stented or unstented, (c) an allograft, (d) a homograft, or (e) a repaired native valve with or without implantation of an annular ring is involved. ${ }^{8}$ Although clinical relevance and therapeutic considerations may be similar, infections of devices or lines placed inside the heart but not connected to the endocardial structures should

Oeynhausen, Germany akohlstaedt@hdz-nrw.de

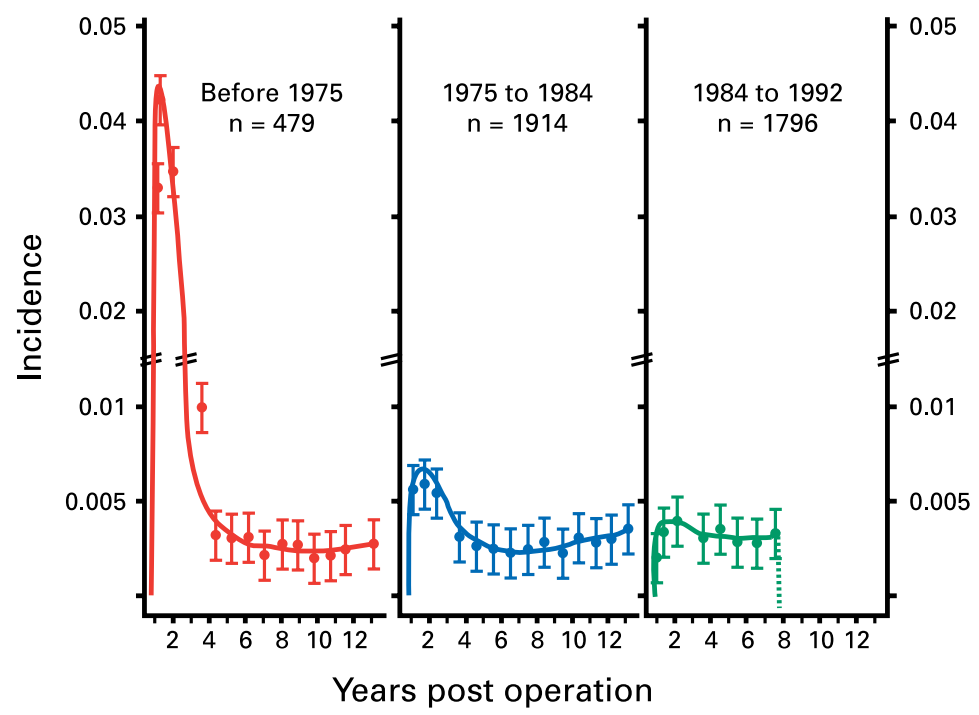

Figure 1. Hazard functions for prosthetic valve endocarditis in 4189 consecutive patients during three successive follow up periods. be classified as "polymer associated infections" rather than PVE.

PVE should be classified as either being acquired perioperatively, and thus nosocomial (early PVE), or as community acquired (late PVE). ${ }^{8}$ Because of significant differences in microbiology of PVE observed within the first year of operation and later on, the time cut off point between early and late PVE should be regarded as one year. ${ }^{9}$

The risk for early PVE is higher (approximately 5\%) in patients with replacement surgery during active infective endocarditis, especially if the causal organism is unknown or the antibiotic treatment is insufficient. The incidence of late PVE is lower for mechanical prostheses than for bioprostheses. The weighted mean incidence for infections of bioprostheses calculated from published series is $0.49 \%$ per patient year for mitral valves and $0.91 \%$ per patient year for aortic valves. For mechanical prostheses, the incidence is $0.18 \%$ per patient year for mitral, $0.27 \%$ per patient year for aortic, and $0.29 \%$ per patient year for multiple implants. ${ }^{10}$

Comparing different periods of implantation, hazard functions reveal a significant decline in early PVE cases in recent years, contrasting with a slight increase in the hazard for late PVE (fig 1).

\section{Pathogenesis}

Prostheses made from metal, pyrolyte or other materials do not allow adherence of microorganisms as long as they are free from thrombotic material. Infections of mechanical prostheses generally originate from the sewing cuff or from thrombi located near the sewing ring downstream in recirculation areas. Inflammatory periprosthetic leaks, ring abscesses, and invasion of the infective process into the adjacent tissue are common findings. The pathogenesis of bioprosthetic infections may be similar to that of native valves. In these cases, the infection is restricted to the cusps, eventually initiating secondary bioprosthetic failure but with only a low tendency to invade the sewing cuff or to result in periprosthetic abscesses. ${ }^{10}$ If the sewing cuff, however, is involved, the pathogenesis and clinical course are more or less the same as in PVE involving mechanical prostheses.

\section{Microbiology}

The microbiology of PVE is very different from that of native valve endocarditis (NVE). Streptococci and enterococci occur less frequently, while staphylococci, bacteria of the HACEK group (Haemophilus, Actinobacillus, Cardiobacterium, Eikinella, and Kingella), and fungi are found more frequently in cases of PVE. Novobiocin susceptible, coagulase negative staphylococci have a particularly high affinity for implanted or indwelling foreign surfaces, especially polymers. ${ }^{4}$ They are the most frequent 


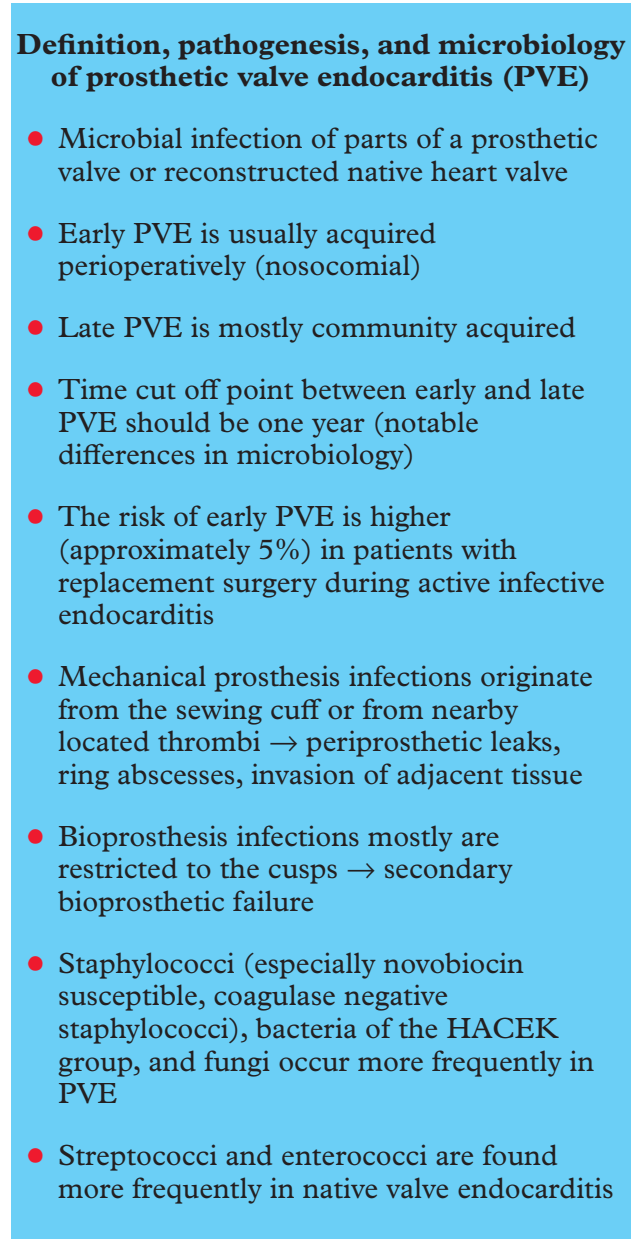

Table 1 Microbiology of early and late PVE. Authors' own findings compared to a recent European literature review

\begin{tabular}{|c|c|c|c|c|}
\hline & \multicolumn{2}{|l|}{ Early PVE (\%) } & \multicolumn{2}{|l|}{ Late PVE (\%) } \\
\hline & $\begin{array}{l}\text { Own experience } \\
(n=34)\end{array}$ & $\begin{array}{l}\text { Europe } \\
(n=68)\end{array}$ & $\begin{array}{l}\text { Own experience } \\
(n=132)\end{array}$ & $\begin{array}{l}\text { Europe } \\
(n=194)\end{array}$ \\
\hline Staphylococcus epidermidis & 29 & 43 & 21 & 28 \\
\hline Staphylococcus aureus & 18 & 13 & 19 & 13 \\
\hline Streptococci & 6 & 3 & $15^{\star}$ & 20 \\
\hline Enterococci & 6 & 2 & 18 & 7.5 \\
\hline HACEK & 18 & 17 & 8 & 7 \\
\hline Fungi & 9 & 6 & 5 & 4 \\
\hline Mixed infections & 6 & - & 3 & - \\
\hline Others & 6 & 12 & 7 & 9 \\
\hline Culture negative & 3 & 4 & 4 & 12 \\
\hline
\end{tabular}

*Viridans group $\mathrm{n}=13(10 \%), \beta$ haemolytic streptococci $\mathrm{n}=3(2 \%)$, and Streptococcus bovis $\mathrm{n}=4$ $(3 \%)$.

HACEK, Haemophilus, Actinobacillus, Cardiobacterium, Eikinella, Kingella.

Table 2 Duration of antimicrobial treatment in prosthetic valve endocarditis with respect to vegetation size and minimal inhibitory concentration (MIC)

\begin{tabular}{llcl}
\hline & \multicolumn{3}{l}{ Vegetation size } \\
\cline { 2 - 4 } & $<4 \mathrm{~mm}$ & $5-9 \mathrm{~mm}$ & $>10 \mathrm{~mm}$ \\
\hline $\mathrm{MIC} \geqslant 4 \mu \mathrm{g} / 1$ & Antibiotic cure & & \\
$4 \mu \mathrm{g} / \mathrm{ml}>\mathrm{MIC} \geqslant 2 \mu \mathrm{g} / \mathrm{ml}$ & $>6$ weeks & Antibiotic cure & \\
$2 \mu \mathrm{g} / \mathrm{ml}>\mathrm{MIC} \geqslant 0.5 \mu \mathrm{g} / \mathrm{ml}$ & 6 weeks & $>6$ weeks & $\begin{array}{l}\text { Antibiotic cure } \\
\text { unlikely }\end{array}$ \\
$0.5 \mu \mathrm{g} / \mathrm{ml}>\mathrm{MIC} \geqslant 0.1 \mu \mathrm{g} / \mathrm{ml}$ & 6 weeks & 6 weeks & $>6$ weeks \\
$\mathrm{MIC}<0.1 \mu \mathrm{g} / \mathrm{ml}$ & 4 weeks & 4 weeks & $>6$ weeks \\
& &
\end{tabular}

^Actual size of vegetation during treatment; MIC, minimal inhibitory concentration of the most effective antibiotic combination. pathogens causing PVE. The usual spectrum for Europe is given in table 1 .

\section{Diagnostic approach}

The diagnostic approach in PVE does not differ from that in NVE, as both are systemic infections maintaining a continuous bacteraemia. Hence, the diagnosis is established if in addition to typical clinical signs and symptoms and positive blood cultures, the device can be shown to be affected by echocardiography, preferably using multiplane transoesophageal (TOE) probes. TOE should be performed without delay in all patients with suspicion of PVE. ${ }^{11}$ For the diagnosis of PVE, TOE is of such immense importance that institutions without this facility are best advised to ask for assistance from a specialised centre. With TOE the size of vegetation can be defined more precisely than with transthoracic echocardiography (TTE), and periannular complications indicating a locally uncontrolled infection (for example, abscesses, dehiscence, fistulas) may be detected earlier. Both size of vegetations and infection morphology significantly influence therapeutic decisions (namely duration of antimicrobial treatment and the need for urgent surgical intervention).

In otherwise unproven cases, gallium-67 scans or indium-111 leucocyte scintigraphy have been reported to be useful in detecting myocardial abscesses or diffuse tissue infiltrations. Their diagnostic impact has not been established so far. ${ }^{12}$

\section{Treatment}

Antimicrobial treatment

The basic principles of antimicrobial treatment in PVE do not differ from those for NVE. Some special aspects need to be considered, however.

PVE is usually associated with vegetations larger than those found in NVE. Consequently, antibiotics have to be used in dosages which result in maximum, non-toxic serum concentrations in order to penetrate the total vegetation. The duration of treatment usually has to be longer than for the treatment of NVE and should consider vegetation size as determined by TOE as well as the minimal inhibitory concentration (MIC) of the most efficient combination of antibiotics (table 2). Antibiotic sterilisation of large vegetations is unlikely with an $\mathrm{MIC} \geqslant 4 \mu \mathrm{g} / \mathrm{ml}$.

In PVE caused by coagulase negative staphylococci, complex interactions between the microorganism and the synthetic material - for example, irreversible adhesion and production of a biofilm, which inhibit the host defence mechanisms-protects against antimicrobial treatment and makes antibiotic sterilisation extremely difficult. ${ }^{56}$

The presence of (micro-) abscesses is likely in PVE caused by coagulase negative staphylococci, and triple therapy including rifampicin (900 $\mathrm{mg} /$ day divided into three doses) is 
recommended. ${ }^{13}$ Rifampicin is actively taken up by granulocytes and becomes effective against intracellular staphylococci and staphylococci inside abscesses. ${ }^{4}$

When PVE is clinically apparent and blood cultures are not yet positive, empiric treatment should be initiated with vancomycin and gentamicin. ${ }^{8}$ For PVE caused by penicillin sensitive streptococci $\left(\mathrm{MIC}_{\mathrm{PEN}}<0.1 \mu \mathrm{g} / \mathrm{ml}\right)$, it is advisable to combine penicillin (20-24 million units/24 hours intravenously (iv) divided into 4-6 doses) with an aminoglycoside (preferably gentamicin, $3 \mathrm{mg} / \mathrm{kg} / 24$ hours iv, divided into 2-3 doses), treating for at least two weeks with this combination and at least a further two weeks with penicillin alone. In the case of penicillin allergy, vancomycin as a single drug treatment $(30 \mathrm{mg} / \mathrm{kg} / 24$ hours iv divided into two doses) or ceftriaxone ( $2 \mathrm{~g} / 24$ hours iv as single dose) in combination with gentamicin should be given. PVE caused by streptococci less sensitive to penicillin $\left(\mathrm{MIC}_{\mathrm{PEN}} \geqslant 0.5 \mu \mathrm{g} / \mathrm{ml}\right)$ or enterococci $\left(\mathrm{MIC}_{\mathrm{PEN}} \leqslant 8 \mu \mathrm{g} / \mathrm{ml}\right)$ are best treated with a combination of penicillin and gentamicin for at least four weeks. Vancomycin can replace penicillin, if the patient is allergic to penicillin or if $\mathrm{MIC}_{\mathrm{PEN}}>8 \mu \mathrm{g} / \mathrm{ml}$. Vancomycin resistant strains susceptible to teicoplanin $\left(\mathrm{MIC}_{\mathrm{TeICOPL}} \leqslant 4 \mu \mathrm{g} / \mathrm{ml}\right)$ may be treated with teicoplanin $(10 \mathrm{mg} / \mathrm{kg}$ iv divided into two doses) plus gentamicin. If the isolates are highly resistant to gentamicin or multiresistant to the standard antimicrobial agents, alternative combinations of drugs (for example, quinolones) must be considered in consultation with an expert in clinical microbiology. Enterococcal PVE is often complicated by periprosthetic dehiscence, annular abscesses or fistulas. In these cases, if antibiotic treatment fails an early surgical intervention should be considered.

If the pathogen is an oxacillin susceptible staphylococcus (MIC $\leqslant 0.1 \mu \mathrm{g} / \mathrm{ml}$ ), gentamicin should be combined with dicloxacillin/ flucloxacillin (12 g/24 hours iv, divided into six doses) for two weeks; thereafter dicloxacillin/ flucloxacillin should be given for an additional four weeks. In oxacillin resistant strains, vancomycin (see above for doses) should replace oxacillin derivates. There is no valid evidence to prove that teicoplanin is superior to the established antistaphylococcal drugs. Early surgery in most cases is indicated to prevent secondary complications. $^{813}$

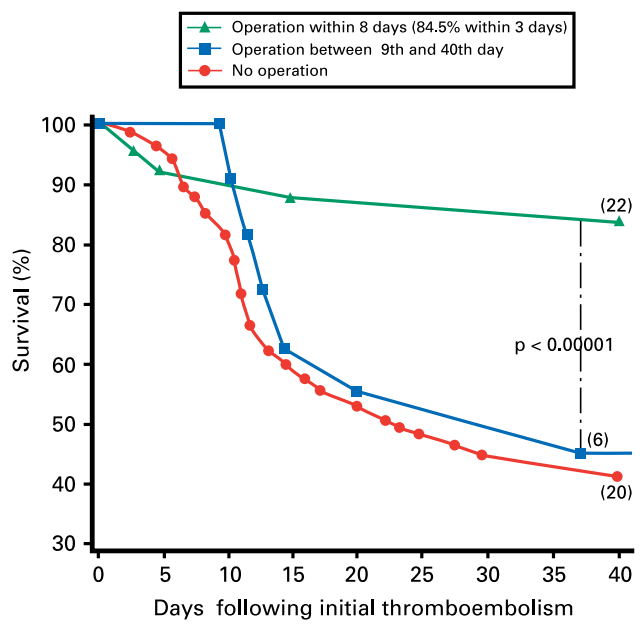

Figure 2. Influence of the timing of surgery on the prognosis of patients with cerebral thromboembolism complicating prosthetic valve endocarditis.

\section{Antithrombotic treatment}

Antithrombotic management in patients with PVE has been discussed widely. ${ }^{14}$ There seems to be a consensus that oral anticoagulation treatment should be suspended and replaced by intravenous heparin. The dosage of heparin depends on the presence and nature of secondary complications (for example, thrombocytopenia) and varies between $7-30 \mathrm{U} / \mathrm{kg}$ body weight. Low molecular weight heparins may be advantageous, as side effects (especially thrombocytopenia) are less frequent.

\section{Surgical reintervention}

If PVE is complicated, it has to be decided whether medical treatment should be continued or urgent surgical intervention is required. The indications for surgery in PVE are similar to those in NVE: large ( $>10 \mathrm{~mm})$, mobile vegetations, thromboembolic events with vegetations still demonstrable, sepsis persisting for more than 48 hours despite effective antibiotic treatment (guided by blood cultures and MICs), and acute renal failure. A cerebral embolic event is not a contraindication for open heart surgery provided that there is no cerebral haemorrhage and the time between embolic event and surgery is short (preferably $<72$ hours) so that the blood-brain barrier can be expected not to be significantly disturbed (fig 2). ${ }^{15}$ Periprosthetic dehiscence with or

Table 3 Guidelines for endocarditis prophylaxis in patients with biological or prosthetic heart valves, categorised according to the patient population at high risk of acquiring endocarditis

\begin{tabular}{|c|c|c|c|}
\hline & \multicolumn{2}{|c|}{ Oropharynx, gastrointestinal tract, urogenital tract } & \multirow[b]{2}{*}{ Skin, heart catheterisation } \\
\hline & No penicillin allergy & In case of penicillin allergy & \\
\hline 1 hour before the procedure & $\begin{array}{l}\text { - Outpatient: } 2 \mathrm{~g}(3 \mathrm{~g}>70 \mathrm{~kg} \\
\text { bodyweight) amoxicillin orally } \\
\text { - Hospitalised: } 2 \mathrm{~g} \text { amoxicillin iv }+ \\
1.5 \mathrm{mg} / \mathrm{kg} \text { gentamicin }\end{array}$ & $\begin{array}{l}\text { Outpatient: } 600 \mathrm{mg} \text { clindamycin orally or } 1 \mathrm{~g} \\
\text { vancomycin iv for } 1 \text { hour or } 800 \mathrm{mg} \text { teicoplanin } \\
\text { - Hospitalised: vancomycin } 1 \mathrm{~g} \text { iv for } 1 \text { hour }+ \\
1.5 \mathrm{mg} / \mathrm{kg} \text { gentamicin }\end{array}$ & $\begin{array}{l}\text { - } 600 \mathrm{mg} \text { clindamycin orally or } \\
1 \mathrm{~g} \text { vancomycin iv for } 1 \text { hour } \\
\text { or } 800 \mathrm{mg} \text { teicoplanin }\end{array}$ \\
\hline 6 hours after the procedure & $\begin{array}{l}\text { - Outpatient: } 1 \mathrm{~g} \text { amoxicillin orally } \\
\text { - Hospitalised: } 1 \mathrm{~g} \text { amoxicillin }+ \\
1.5 \mathrm{mg} / \mathrm{kg} \text { gentamicin }\end{array}$ & $\begin{array}{l}\text { - Outpatient: } 300 \mathrm{mg} \text { clindamycin orally } \\
\text { Hospitalised: vancomycin } 1 \mathrm{~g} \text { iv for } 1 \text { hour }+ \\
1.5 \mathrm{mg} / \mathrm{kg} \text { gentamicin }\end{array}$ & - $300 \mathrm{mg}$ clindamycin \\
\hline
\end{tabular}

iv, intravenous. 
Treatment and prophylaxis of prosthetic valve endocarditis (PVE)

Duration of treatment for PVE is usually longer than for native valve endocarditis

- Antibiotic sterilisation of coagulase negative staphylococci or enterococci PVE is extremely difficult

- Early surgical intervention is necessary in most cases to prevent secondary complications

- Oral anticoagulation should be replaced by intravenous heparin or low molecular weight heparin

- For PVE prophylaxis, antibiotics should be taken one hour before and six hours after the interventional procedure

- In hospitalised patients, antibiotics may be administered intravenously in combination with aminoglycosides

without myocardial failure has a poor prognosis. If congestion is not promptly removed by medical treatment, surgical intervention is mandatory. Allograft aortic root replacement is a valuable technique in the complex setting of PVE with involvement of the periannular region. ${ }^{16}$

\section{Prophylaxis}

As the risk for an infection is much higher in patients with prosthetic heart valves than in patients with valvar heart disease, more intensive prophylaxis is needed in these patients. In patients with prosthetic valves, the antibiotics should be taken one hour before the interventional procedure and a repeat but reduced dosage administered six hours after the procedure. If patients are hospitalised, the antibiotics may be applied intravenously in combination with aminoglycosides one hour before and six hours after the procedure (table 3 ).

1. Blackstone EH, Kirklin JW. Death and other time-related events after valve replacement. Circulation 1985;72:753-67.

- Experience with 1533 patients undergoing valve surgery between 1975 and 1979 revealed that PVE occurs uncommonly after original valve replacement surgery

2. Kloster FE. Complications of artificial heart valves. JAMA 2. Kloster FE. Comp

3. Vlessis AA, Khaki A, Grunkemeier GL, et al. Risk, diagnosis and management of prosthetic valve endocarditis: a review. J Heart Valve Dis 1997;6:443-65.

a revis. provides an outline for diagnosis and treatment based on the published literature and on the authors' personal clinical experiences.

4. Zimmerli W. Experimental models in the investigation of device-related infections. J Antimicrob Chemother 1993:31 (suppl D):97-102.

5. Horstkotte D, Weist K, Rueden H. Better understanding of the pathogenesis of prosthetic valve endocarditis-recen erspectives for prevention strategies. J Heart Valve Dis 1998:7:313-15.

Editorial on the recent perspectives for prevention of PVE.

6. Hyde JAJ, Darouiche RO, Costeron JW. Strategies for prophylaxis against prosthetic valve endocarditis. A review article. J Heart Valve Dis 1998;7:316-26.

- This article gives the historic background to the prevention of PVE and discusses the current state of research in this area.

7. Edmunds LH, Clark RE, Cohn LH, et al. Guidelines for reporting morbidity and mortality after cardiac valvular operation. Ann Thorac Surg 1988:46:257-9.

8. Horstkotte D, Follath F, v Graevenitz A, et al. Recommendations for prevention, diagnosis and treatment of infective endocarditis. The task force on infective endocarditis of the European Society of Cardiology. Eur Heart $J$ (in press)

- A European consensus status giving the latest guidelines for prevention, diagnosis, and treatment of infective endocarditis.

9. Karchmer AW, Gibbons GW. Infections of prosthetic heart valves and vascular grafts. In: Bisno AL, Waldvogel FA, eds. Infections associated with indwelling medical devices. Washington: ASM Press, 1994:213-49.

10. Horstkotte D, Piper C, Niehues R, et al. Late prosthetic valve endocarditis. Eur Heart $J$ 1995;16(supp B):39-47.

- Prevalence, sources of infection, microbiology, diagnostic approach, and medical as well as surgical treatment of operated on in Düsseldorf between 1970 and 1992.

11. Pedersen WR, Walker M, Olseon JD, et al. Value of transesophageal echocardiography in evaluation of native and prosthetic valve endocarditis. Chest 1991:100:351-6.

- This study reported better visualisation of valvar vegetations in native as well as in prosthetic valve vegetations in native as well as in prosthetic valve
endocarditis with transoesophageal (TOE) than with endocarditis with transoesophageal (TOE) than with
transthoracic (TTE) echocardiography. TTE was positive in transthoracic (TTE) echocardiography. TTE was positive in
only 5 of 10 patients with infective endocarditis, while TOE not only yielded abnormal findings in all 10 patients but also revealed additional information in 4 of 5 patients.

12. O'Brien K, Barnes D, Martin RH, et al. Gallium-SPECT in the detection of prosthetic valve endocarditis and aortic ring abscess. J Nucl Med 1991;32:1791-3.

13. Wilson WR, Geraci JE, Danielson GU, et al. Anticoagulant therapy and central nervous system complications in patients with prosthetic valve endocarditis. Circulation 1978;57:1004-7.

- Adequate anticoagulant treatment in patients with PVE resulted in fewer central nervous system complications than inadequate anticoagulation.

14. Wilson WR, Karchmer AW, Dajani AS, et al. Antibiotic treatment of adults with infective endocarditis due to streptococci, enterococci, staphylococci, and HACEK microorganisms. JAMA 1995;274:1706-13.

- Consensus opinion regarding management of PVE caused by commonly encountered microorganisms and those cases resulting from infrequent causes of PVE.

15. Horstkotte D, Piper C, Wiemer M, et al. Dringlicher Herzklappenersatz nach akuter Hirnembolie während floride Endokarditis. Med Klinik 1998;93:284-93.

- The analysis of an urgent surgical intervention after embolic cerebral infarction in 22 patients compared to 27 medically treated patients revealed that rempared to medically treated patients revealed that removing the beneficial and that surgery should be performed within 72 hours to prevent secondary cerebral haemorrhage.

16. Dossche KM, Defauw JJ, Ernst SM, et al. Allograft aortic root replacement in prosthetic aortic valve endocarditis: a review of 32 patients. Ann Thorac Surg 1997:63:1644-9.

- This review of 32 patients showed that allograft aortic root replacement is a valuable technique in the complex setting of PVE with involvement of the periannular region with low perioperative mortality and morbidity. 